\title{
Conversion of Non-Biodegradable Plastic Waste into Decomposable Waste using Mealworm Named "Tenebrio Molitor"
}

\author{
Ahmed Ejaz Fazal, Mahesh K V, S.Aravindan, Rajashri Melannavar
}

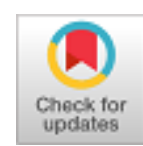

\begin{abstract}
Plastic has made tremendous contribution in day to day lives of humans. Today like medical, agricultural, packaging, household, piping and other items of daily use. Plastic used in household system like food cover packets, sachets, Styrofoam cups, glasses, etc., this research involves the Conversion of non-biodegradable plastic waste into decomposable excreta by mealworms. A worm in which the bacteria is present in its gut. It has an ability to digest the complex plastic waste into smaller organic excreta. One of the methods to reduce plastic waste at household system is by using worms whose scientific name is "Tenebrio Molitor" Mealworm has proved to be an efficient method of reducing plastic to some extent and mealworm are grow rapidly within a span of 3 months and it can be grown in most of normal climate and natural condition. The methodology involves collecting and rearing of mealworms at standard temperature in different trays at University of Agricultural Sciences, Ghandi Krishi Vignan Kendra Bellary Road, Bangalore. Obtained results show the average weight $40.1775 \mathrm{mg}$ of Styrofoam was consumed by 25 number of worms mealworms in 3 days. Therefore it can be concluded that 100 numbers of mealworms consumes $53.57 \mathrm{mg}$ of Styrofoam in one day.
\end{abstract}

Keywords: Mealworms, Plastic, Styrofoam, Vermicomposting

\section{INTRODUCTION}

Plastic is a material consisting of a good number of artificial or semi-synthetic organics that can be malleable and may be molded into solid objects of various shapes. Plastic is usually organic polymers of high molecular mass. With the increase in population the plastic garbage is also increasing. Modern lifestyle needs disposable product, like soda cans or water bottle, however the accumulation of those product has resulted in increasing amounts of plastic pollution round the world. As plastic consists of harmful pollutants, it cause a significant threat to atmosphere.

Revised Manuscript Received on October 30, 2019.

* Correspondence Author

Ahmed Ejaz Fazal*, Assistant Professor, Department of Civil Engg, Sri Venkateshwara College of Engineering, Bangalore, Karnataka, India. Email: ejazfazal23@gmail.com

Mahesh K V, Assistant Professor, Department of Civil Engg, Sri Venkateshwara College of Engineering, Bangalore, Karnataka, India. Email: maheshkv035@gmail.com

S Aravindan, Assistant Professor, Department of Civil Engg, Sri Venkateshwara College of Engineering, Bangalore, Karnataka, India Email: aravindan1803@yahoo.com

Rajashri Melannavar, Assistant Professor, Department of Civil Engg, Nagarjuna College of Engineering \& Technology, Bangalore, Karnataka, India Email: aravindan1803@yahoo.com

(C) The Authors. Published by Blue Eyes Intelligence Engineering and Sciences Publication (BEIESP). This is an open access article under the CC BY-NC-ND license (http://creativecommons.org/licenses/by-nc-nd/4.0/)
It appears rather obvious that this much quantity of plastic will not break down, and can create havoc on natural environments, resulting in long-term problems for plants, animals, and people. Few long-term effects of plastic pollution are:

\section{- It disturb the Food Chain \\ - Groundwater Pollution \\ - Land Pollution \\ - Air Pollution \\ - Threat to animals}

Land pollution is the most visible types of pollution. Land pollution not only can hurt animals and their habitats, but also is unpleasant and destroys the beauty of nature. It is roughly calculated that more or less ten thousand tons per day (TPD) of plastics waste is generated i.e. 9\% of 1.20 lacs TPD of MSW within the country. The plastics waste constitutes 2 major classes of plastics

- Thermoplastics

- Thermoset plastics.

Thermoplastics' constitutes 80 per cent and thermoset constitutes approximately 20 per cent of total post-consumer plastics waste generated in India.

The environmental hazards because of mismanagement of plastics waste embody the subsequent aspects:

1. Untidy plastics spoils beauty of the place and makes it unpleasant aesthetically, choke drains, and makes vital public places filthy.

2. Garbage containing plastics, on burning causes air pollution by emitting polluting gases.

3. Garbage mixed with plastics interferes in waste treatment facilities and will cause issues in operations of landfills.

\section{Plastic Bags and Environment}

The same properties that are responsible for making plastic luggage bags commercially booming and ubiquitous - namely their low weight and resistance to degradation have conjointly contributed to their proliferation within the atmosphere, because of their sturdiness, plastic luggage bags will take centuries to decompose, hence creating huge environmental menace such as choking the drainage systems, creating impervious layer arresting groundwater recharge and killing animals. Plastic luggage bags are produced utilizing organic and inorganic additives like colorants and pigments, plasticizers, antioxidants, stabilizers and metals. A number of these are cancer causing agents and certain to contaminate food stuffs, if packed in these. [5]. 


\section{Purpose of Study}

To study the life cycle of "Tenibrio Molitor". Its different life stages on consumption of plastic. Analysing the effect of mealworm's on different grades of plastic. Study on the duration required by the mealworms for necessary digestion. Conversion of non-biodegradable plastic waste into decomposable excreta by mealworms

\section{Worms}

The Mealworm isn't a worm; it's a larva. Any similarity to a real worm is incidental. Meal worm larvae has golden yellow color and have twelve segments - a head, 3 pectoral segments, and 9 abdominal segments Mealworm larvae are the counterpart of the acquainted caterpillar within the butterfly story. They pull themselves around on six short legs, one pair on every pectoral section [2].

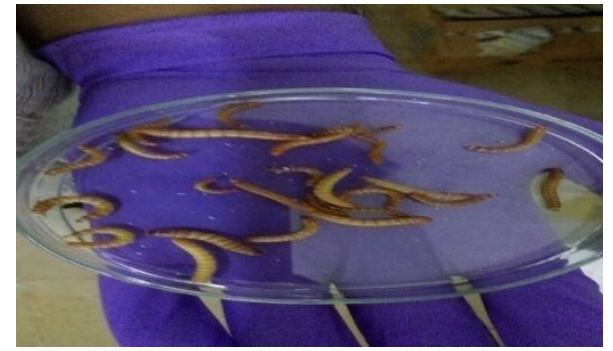

Fig. 1 Mealworms

\section{Life Cycle of Meal Worms (Tenebrio Molitor)}

Darkling beetles follow a life history referred to as complete metamorphosis. Like butterflies and moths, they're going through four distinct stages throughout their life cycle. A female beetle lays eggs, as several as five hundred in her temporary lifespan of a month or 2. In couple of weeks, the little larvae emerge from the eggs. The larvae is referred as mealworms, however they're not real worms. The larvae are golden yellow and have twelve body segments. They're the counterpart of the acquainted caterpillar within the butterfly story. Mealworms pull themselves around on six short legs that are all huddled at the front. The larvae appear to have 2 functions in life: eat and grow. Beetles are arthropods, and similar to all members of their phylum they wear their skeleton on the surface like a suit of armor. This often safeguards, when they are attacked however it is terribly inconvenient when they are attempting to grow. The arthropods have solved this drawback by shedding (molting) their shell sporadically. After shedding, the soft white larvae expand before the new larger shell hardens. This method might repeat six or more times over a period of 3-month, At third stage the larvae are two cm (3/4") long. The ultimate larval molt reveals future stage, the pupa. The pupae do not eat and that they do not move apart from a twitch or 2 once disturbed. Inside, however, the Mealworm is growing into a beetle, looks similar to a caterpillar turning into a butterfly while hidden within the pupa. In two or three weeks the it splits open and out walks a beetle, white initially, however turning to brown subsequently and eventually black. The beetles mate and lay eggs, and therefore the cycle repeats.

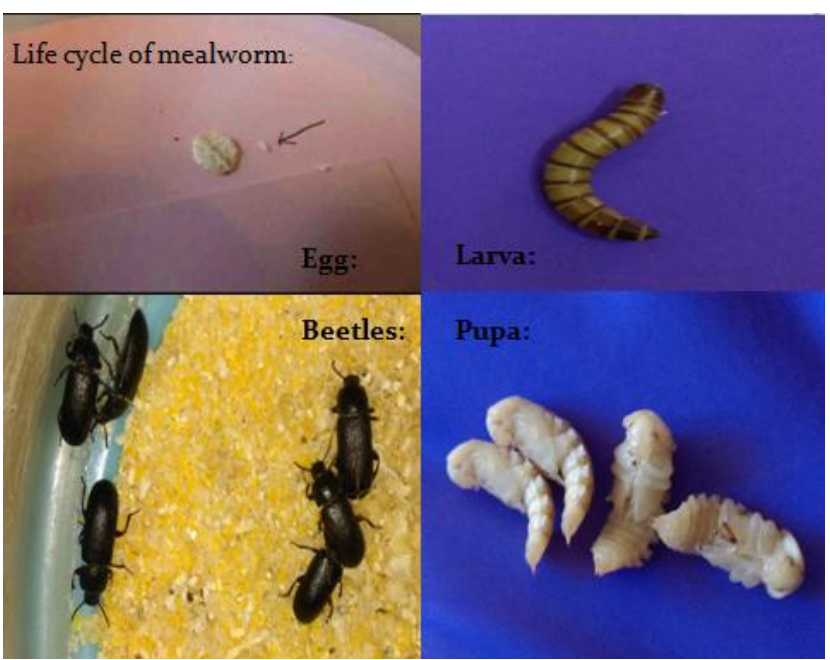

Figure 2: Life cycle of mealworm

\section{METHODOLOGY}

Plastic waste was procured from the source, classified and separated the waste for a suitable quantity for analysis and for conduction of experiments.

\section{Materials}

Plastic waste - Plastic that is normally used at household systems like thermo coal cups, disposable cups and bends (Styrofoam) and egg cartons, daily food plates, packing bags, milk cover (polythene).

Table 1: Grade classification of plastic

\begin{tabular}{|c|c|}
\hline Type of plastic & Grade of plastic \\
\hline Styrofoam & 6 \\
\hline Low plastic content & 4 \\
\hline Polypropylene & 5 \\
\hline
\end{tabular}

The methodology that was adopted for analysis of plastic consumption by mealworms is "Vermicomposting".

Collecting and rearing of mealworms at standard temperature in different trays. Collecting different - grades of plastic (normally used in day to day life at household system).Place the mealworms in five different trays along with different grades of plastic. Note down the contact time required by the mealworms for the consumption of plastic. Degrade the plastic using vermicomposting technique (using a dustbin aerobically). Six empty boxes were taken to keep the worms for digestion process. 50 worms were put in each box, making a total of 5 boxes and 100 worms in the remaining one. Different grades of plastic of known weights were added to these boxes. Observations were taken at room temperature in an open atmosphere for the entire digestion process.

\section{Rearing Of Worms}

The Tenebrio Molitor can survive at normal room temperature but for rearing it need some incubation temperature. The incubation temperature can be achieved by keeping it in a closed box without disturbing it for some days. 
Select the boxes such a way that there should be some perforated openings (like mesh) on top. Cut the bottom of the box such that, the eggs laid by the beetles will directly drop into another box which is placed below especially for the collection of egg. It takes about 7-10 for hatching of eggs after laying. Once the egg hatches, the larva starts feeding on plastic. Later, larva stage transmits to pupa stage and it is an inactive stage (it is not being useful for experiments). The pupa will turn into beetles; this is meant for hatching of eggs.
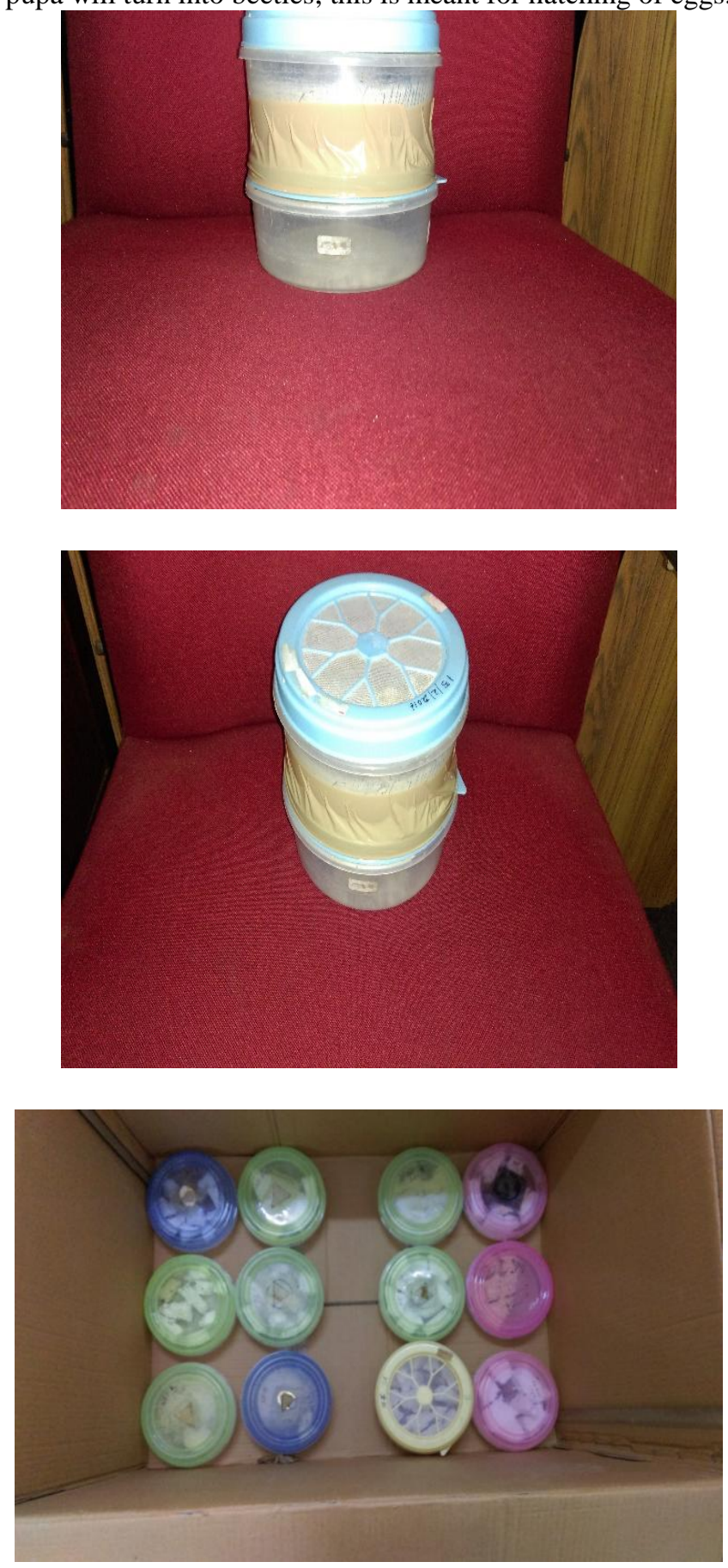

Figure 3: Rearing Of Worms

\section{EXPERIMENTAL SETUP}

Six empty boxes were taken to keep the worms for digestion process. 50 worms were put in each box, making a total of 5 boxes and 100 worms in the remaining one. Different grades of plastic were added to those boxes with worms. Observations were taken at room temperature in an open atmosphere

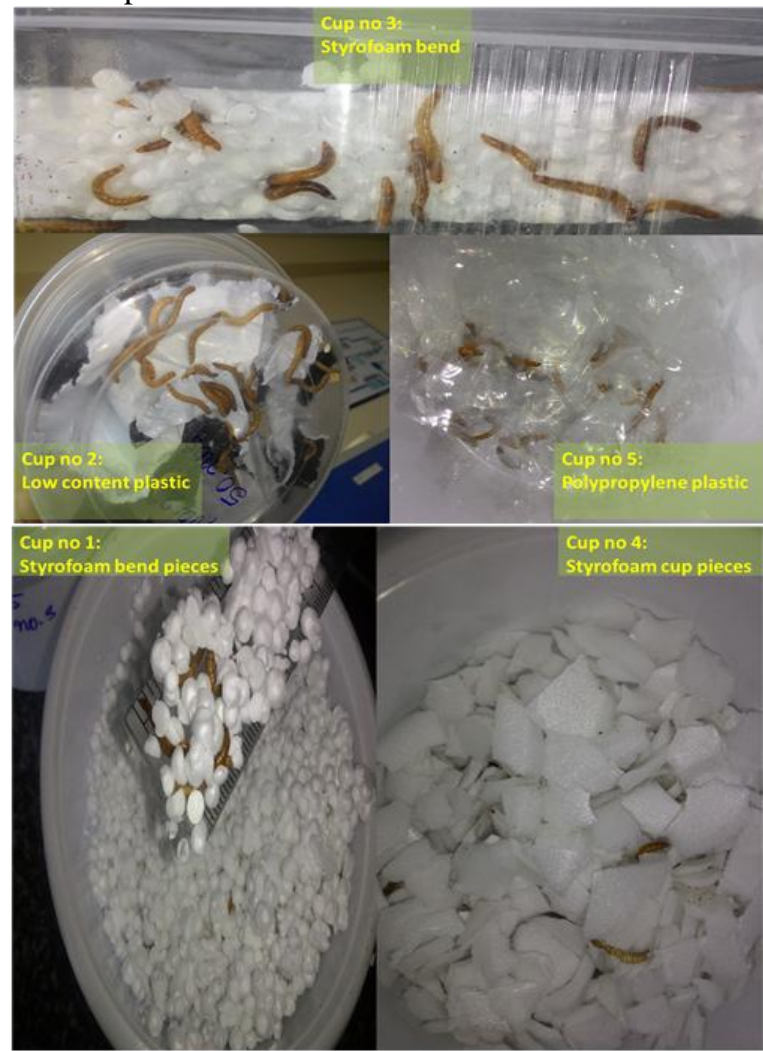

Fig. 4 : Types of Plastic in Boxes with mealworms

\section{RESULT AND DISCUSSION}

The consumption of plastic depends on type of plastic fed to worms. From the 1st trial of observation we found that, the worms have more affinity or ability of eating the plastic in Styrofoam. But also it eat the other type of plastic not that much as Styrofoam. So, further studies are only on Styrofoam. From all trials we come to know that the worms can survive by eating Styrofoam as food, the worms can eat Styrofoam with food or without food (not effecting the growth of worms) the best way to feed Styrofoam is both, food and Styrofoam in equal proportions.

Table II: Details of Weight of worms and Types of Plastic added in a box

\begin{tabular}{|c|c|c|c|c|c|c|}
\hline $\begin{array}{c}\text { Type Of } \\
\text { Plastic }\end{array}$ & $\begin{array}{c}\text { Box } \\
\text { Nu } \\
\mathbf{m b} \\
\text { er }\end{array}$ & $\begin{array}{c}\text { Weigh } \\
\text { t of } \\
\text { Box } \\
\text { (mg) }\end{array}$ & $\begin{array}{c}\text { Weight } \\
\text { of } \\
\text { Plastic } \\
\text { added } \\
\text { (mg) }\end{array}$ & $\begin{array}{c}\text { Weight } \\
\text { of } \\
\text { worms } \\
\text { (mg) }\end{array}$ & $\begin{array}{c}\text { Num } \\
\text { ber } \\
\text { Of } \\
\text { Wor } \\
\text { ms }\end{array}$ & $\begin{array}{c}\text { Total } \\
\text { Weig } \\
\text { ht } \\
\text { (mg) }\end{array}$ \\
\hline $\begin{array}{c}\text { Styrofoam : } \\
\text { (thermo col } \\
\text { powder)- }\end{array}$ & $1^{\mathrm{ST}}$ & 19126 & 1000 & 2398 & 50 & 22524 \\
\hline $\begin{array}{c}\text { Low plastic } \\
\text { content } \\
\text { plastic } \\
\text { pieces: }\end{array}$ & $2^{\mathrm{ND}}$ & 15263 & 928 & 1690 & 50 & 17881 \\
\hline $\begin{array}{c}\text { Styrofoam: } \\
\text { (thermo col } \\
\text { bend) - }\end{array}$ & $3^{\mathrm{RD}}$ & 30655 & 2420 & 2604 & 100 & 35679 \\
\hline $\begin{array}{c}\text { Styrofoam } \\
\text { cups } \\
\text { pieces: }\end{array}$ & $4^{\mathrm{TH}}$ & 19080 & 3037 & 2530 & 50 & 24647 \\
\hline
\end{tabular}

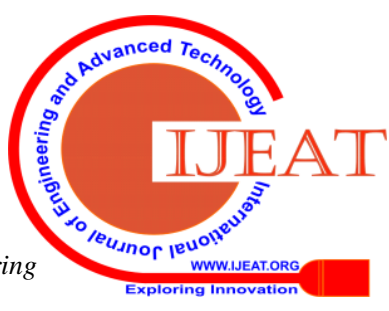




\begin{tabular}{|l|l|l|l|l|l|l|}
\hline $\begin{array}{c}\text { Polypropyl } \\
\text { ene plastic: }\end{array}$ & $5^{\mathrm{TH}}$ & 20494 & 1861 & 1407 & 50 & 23762 \\
\hline
\end{tabular}

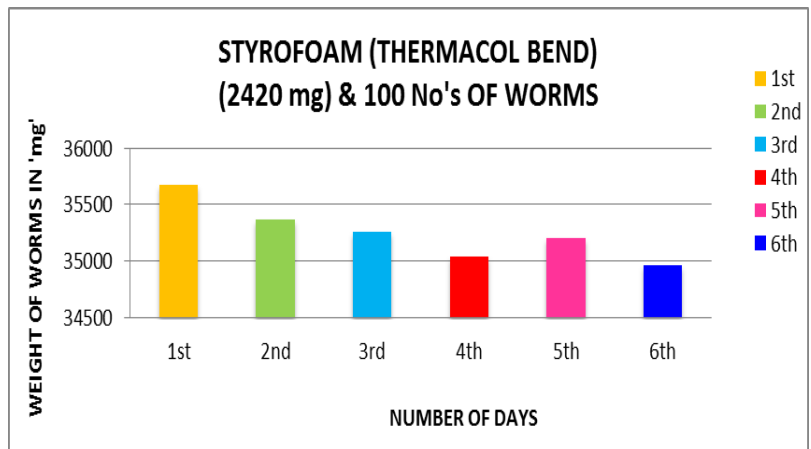

Figure 5: Styrofoam (Thermacol Bend) (2420 Mg) \& 100 No's Of Worms

\section{CONCLUSION}

It can be concluded that the mealworm can be successfully used as one of the method to reduce the plastic content for some extent by a safe vermicomposting method. Mealworms are proved to be an efficient method of reducing some extent of plastic and mealworm can grow rapidly within a span of 3 months and it can be grown in most of normal climate and natural condition. Vermicomposting is an eco-friendly method for reduction of plastic in a biodegradable manner. It is evident that the rate is high, when feeding of plastic with food i.e., around $80 \mathrm{mg}$ of plastic consumed by worm when the food was also fed to worm. Lesser the age of worms less is the consumption of plastic. The consumption is more, when all sizes of worms are mixed. The residue produced after digestion of plastic by worms is completely free from plastic. This process results in discharging non-biodegradable waste into degradable manure. This manure can be used for gardening purpose. The above table are by taking average of weight, got results around $40.1775 \mathrm{mg}$ of Styrofoam was consumed by mealworms in 3 days by 25 numbers of worms. Therefore, 100 numbers of worms consumes $53.57 \mathrm{mg}$ of Styrofoam in one day.

\section{REFERENCES}

1. Jun Yang, Yu Yang, Evidence of Polyethylene Biodegradation by Bacterial Strains from the Guts of Plastic-Eating Waxworms Bio-Inspired Smart Interfacial Science and Technology of Ministry of Education, School of Chemistry and Environment, Beihang University, Beijing 100191, P. R. China.

2. Yu Yang, Jun Yang, Biodegradation and Mineralization of Polystyrene by Plastic-Eating Mealworms: Chemical and Physical Characterization and Isotopic Tests Environmental Science \& Technology 201549 (20), 12080-12086.

3. Martin C. Krueger, Bettina Seiwert, Andrea Prager, and Degradation of polystyrene and selected analogues by biological Fenton chemistry approaches: Opportunities and limitations Dietmar Schlosser Chemosphere 2017 173, 520-528.

4. Christopher J. Howe, Federica Polyethylene bio-degradation by caterpillars of the wax moth Galleria mellonella Paolo Bombelli, Bertocchini Current Biology 201727 (8), R292-R293.

5. A. A. Akinola A. Adeyemi and F. M. Adeyinka, A Proposal for the Management of Plastic Packaging Waste IOSR Journal Of Environmental Science, Toxicology And Food Technology (IOSR JESTFT)

6. Javeriya Siddiqui and Govind Pandey A Review of Plastic Waste Management Strategies International Research Journal of Environment Sciences ISSN 2319-1414 Vol. 2(12), 84-88, December (2013)
7. Hayelom Dargo Beyene Recycling of plastic waste into fuels, a review International Journal of Science, Technology and Society 2014; 2(6): 190-195

8. Hyunseong Kim A Study on the Utilization of the Earthworms Eisenia fetidaand Eisenia Andrei for the Disposal of Polymers International Journal of Environmental Science and Development, Vol. 7, No. 5, May 2016

\section{AUTHORS PROFILE}

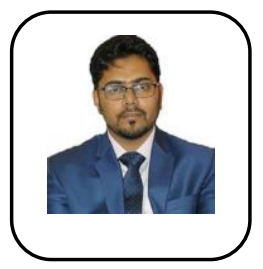

Ahmed Ejaz Fazal, Assistant Professor with 5 years of teaching experience, Graduated from M.E in Geotechnical Engineering from University Visvervaraya College of Engineering, Qualified Gate in 2013, Published 4 Scopus Indexed Journals, interested in research related to Geo-environment.

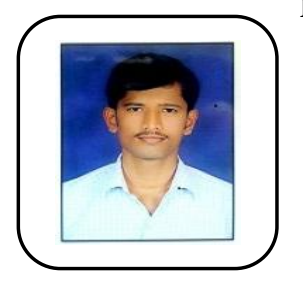

Mahesh K V, Assistant Professor, SVCE, Bangalore, having 2 years of teaching experience, graduated from Nagarjina College of Engineering and Technology in Construction Technology, Published 2 SCI journals

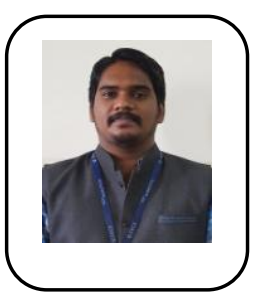

ARAVINDAN S, Assistant professor, SVCE, Bengaluru. Having 3yrs of experience in Water Resources Engineering, graduated from College of Engineering, Guindy and pursued B.E in Civil Engineering from Anna University, Chennai. I have published my research in SCI journals. My project on WDS design for rural area is recognized by KSCTC

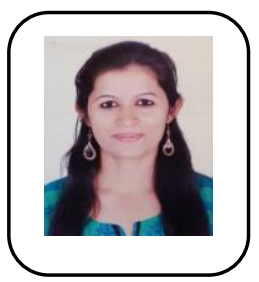

RAJASHRI MELANNAVAR, Assistan professor, Nagarjuna College of Engineering \& Technology, Bengaluru. Having 6 yrs of experience in Environmental Engineering, graduated from PES, Mandya and pursued B.E in Environmental Engineering from AIT, Chigmangalur. Published 3 SCI Journals. Received grants from KSCST 